\title{
Haptoglobin Typing, is It Clinically Necessary for a Reliable Determination of Haptoglobin with the Single Radial Immunodiffusion Technique?
}

\author{
By H.J.M. van Rijn \\ Clinical and Haematological Laboratory
}

W. H. J. Kruit

Department of Internal Medicine

Dr. A. Mathijsen Hospital, Utrecht, The Netherlands and

\section{J. Schrijver}

Department of Clinical Biochemistry, Institute CIVO-Toxicology \& Nutrition TNO, Zeist, The Netherlands

(Received August 15, 1983)

Summary: Over a period of three years we determined haptoglobin levels by single radial immunodiffusion (RID) and the haptoglobin phenotype in over 1700 samples of patients suspected of a haemolytic disease.

As haptoglobin phenotyping is rather laborious and therefore an expensive method, we re-evaluated the diagnostic need for phenotyping.

From our reference values for the respective phenotypes of haptoglobin it may be theoretically argued that phenotyping is still desirable when the RID value is in the range $400-1170 \mathrm{mg} / \mathrm{l}$. Limiting ourselves to suspected haemolytic diseases, one can abolish phenotyping beyond this narrow range without withdrawing important clinical information. From the total group it appeared that 480 samples lay in this range. In 72 samples $(15 \%$ of 480$)$ the evaluation of the RID values was essentially altered by phenotyping. Careful examination of the medical records indicated that in a number of cases laborious phenotyping had indeed contributed to the diagnosis.

Ist die Haptoglobin-Typisierung klinisch erforderlich für eine zuverlässige Bestimmung von Haptoglobin mit der einfachen radialen Immunodiffusion?

Zusammenfassung: Wir bestimmten in über 1700 Proben von Patienten mit Verdacht auf eine hämolytische Erkrankung während drei Jahren die Haptoglobinkonzentration mit der einfachen radialen Immundiffusion und zugleich den Haptoglobin-Phänotyp.

Wir prüften erneut die diagnostische Notwendigkeit der Phänotypisierung, da diese arbeitsaufwendig und deshalb teuer ist.

Aus unseren Referenzwerten für die entsprechenden Phänotypen von Haptoglobin kann theoretisch abgeleitet werden, daß Phänotypisierung noch wünschenswert ist, sofern die mit radialer Immundiffusion bestimmte Konzentration im Bereich von 400-1170 mg/l liegt. Bei Beschränkung auf Verdachtsfälle hämolytischer Erkrankungen kann die Phänotypisierung oberhalb dieses schmalen Bereichs ohne Verlust wesentlicher klinischer Information unterlassen werden. In diesem Bereich lagen 480 Proben der gesamten Gruppe. Bei 72 (15\% von 480) Proben änderte sich aufgrund der Phänotypisierung die Beurteilung der Ergebnisse der radialen Immundiffusion. Eine sorgfältige Durchsicht der Krankenblätter zeigte, daß in einer Anzahl von Fällen die arbeitsaufwendige Phänotypisierung tatsächlich zur Diagnose beitrug. 


\section{Introduction}

A number of analytical methods are available to the clinician when searching for the cause of a haemolytic disease. In cases of haemolysis, determination of the decreased red blood cell survival and of the number of reticulocytes can be helpful in the diagnosis.

However, in comparatively mild forms of a haemolytic process, the reticulocyte count lacks conclusiveness and any diagnosis derived from it is doubtful (1).

Recently, Marchand et al. (2) supported the routine use of the serum haptoglobin determination in the diagnosis of haemolytic diseases.

There exists, however, a large biological inter-individual variation in normals, so that the clinical usefulness of a single haptoglobin value has been questioned (3).

Moreover, one has to take into account the fact that haemolytic diseases are often accompanied by inflammatory processes which tend to offset the lowering of the haptoglobin level that goes with the haemolytic condition.

Besides other parameters, haptoglobin is determined routinely in our clinic to support the diagnosis of haemolytic disease; for this purpose single radial immunodiffusion is used (4). However, in using this technique a calculation of the exact level of haptoglobin requires the determination of the haptoglobin phenotype, which is time-consuming and expensive.

We therefore raised the question of whether and when the phenotype determination can be omitted for clinical purposes. We considered only low haptoglobin levels, which are indicative of intravascular haemolysis of a deficient liver haptoglobin synthesis. Haptoglobin levels above normal, which can be indicative of an inflammatory process, were not taken into consideration.

We evaluated the serum haptoglobin levels determined over a period of three years in a wide variety of patients with suspected haemolytic disease. All levels without and with typing were considered, attention being focussed on levels which changed from normal to lowered and the number of levels which changed from lowered to normal as a result of phenotyping.

\section{Materials and Methods}

Reagents, equipment and methods were as described previously (5).

Mancini's method (4) was used for the RID technique. Typing of haptoglobin was done by polyacrylamide gel electrophoresis (5).

Serum samples were all from patients with suspected haemolysis. The main findings in the peripheral blood were anaemia and/or reticulocytosis, sometimes accompanied by elevated serum bilirubin levels and/or increased serum lactate dehydrogenase levels.

\section{Results and Discussion}

During a three year period, 1744 patient samples were received in our laboratory, $86.3 \%$ from men and $13.7 \%$ from women. This rather unusual distribution arises because the patients in our hospital are basically army personnel.

According to the gel electrophoresis pattern six patients showed the Johnson type of haptoglobin, while the serum haptoglobin level in 106 patients was too low (below $200 \mathrm{mg} / \mathrm{l}$ ) to determine the haptoglobin phenotype. For the remaining 1632 samples the total haptoglobin level (untyped) and the phenotype (1-1, 2-1 or 2-2) were determined. For the untyped haptoglobin level the over-all reference range of 500$3300 \mathrm{mg} / \mathrm{l}$ was used, while for the phenotypes $1-1$, $2-1$, and 2-2 the reference ranges were $700-2300$, $900-3600$ and $600-2900 \mathrm{mg} / \mathrm{l}$ serum, respectively (5). The factors taking into account the three phenotypes were $0.6,1.3$, and 1.5 respectively, in accordance with the information of the manufacturer of the RID plates.

As already mentioned the aim of this retrospective study was to answer the question of whether it is always necessary to perform a haptoglobin phenotyping. On theoretical grounds one can decide to perform phenotyping when total haptoglobin is in the range $400-1170 \mathrm{mg} / \mathrm{l}$. This idea is based on the reference ranges for the three genetic types and their respective conversion factors and can be exemplified as follows.

A patient sample with a value $\mathrm{Hp}=1160 \mathrm{mg} / \mathrm{l}$ and belonging to type Hp 1-1 becomes $690 \mathrm{mg} / \mathrm{I}$ when the genetic type is taken into account. The reference range for this type is $700-2300 \mathrm{mg} / \mathrm{l}$. Hence, values below $1170 \mathrm{mg} / \mathrm{l}$ are "lowered" when the genetic type is $\mathrm{Hp} \mathrm{1-1}$ and the appropriate factor is applied. It is therefore valid to question the necessity of typing all the serum samples with values lower than $1170 \mathrm{mg} / \mathrm{l}$. This question can be answered by considering the reference ranges of the genetic types $(5,6)$ and their factors. A serum sample with a $\mathrm{Hp}$ value below $400 \mathrm{mg} / \mathrm{l}$ is "lowered" whatever the genetic 
type. Higher values come within the reference range if the genetic type happens to be $\mathrm{Hp} \mathrm{2-2,} \mathrm{because} \mathrm{the}$ conversion factor for this type is 1.5.

As already mentioned, if the level is above normal, indicating for instance an acute inflammatory process, phenotyping can also be ignored. This is because we are interested only in whether this determination supports the diagnosis of a haemolytic disease.

It appeared that in our total sample group (1632 samples) a large number (480 samples) had values between 400 and $1170 \mathrm{mg} / \mathrm{l}$. So if one decides to ignore Hp phenotyping, and to perform this determination only when the values of the total haptoglobin determination lie in the range 400 to $1170 \mathrm{mg} /$, one can considerably reduce the work load and the costs of this test.

In this context the question arises as to the distribution of the observed haptoglobin values both without and with phenotyping. As can be seen from table 1,

Tab. 1. The distribution of the observed total haptoglobin values (untyped) and typed haptoglobin values of our patient groups, according to the reference values given in the text.

\begin{tabular}{llrrr}
\hline & $\begin{array}{l}\text { Haptoglobin } \\
\text { typed }\end{array}$ & \multicolumn{2}{c}{ Haptoglobin untyped } \\
& & Lowered & Normal & Elevated \\
\hline Type 1-1 & Lowered & 3 & 10 & 0 \\
$\mathrm{n}=255$ & Normal & 0 & 175 & 21 \\
& Elevated & 0 & 0 & 46 \\
Type 2-1 & Lowered & 12 & 26 & 0 \\
$\mathrm{n}=757$ & Normal & 0 & 516 & 0 \\
& Elevated & 0 & 46 & 157 \\
Type 2-2 & Lowered & 29 & 0 & 0 \\
$\mathrm{n}=620$ & Normal & 36 & 395 & 0 \\
& Elevated & 0 & 108 & 52 \\
\hline
\end{tabular}

$\mathrm{n}_{\mathrm{t}}=1632$

10 samples ( $3.9 \%$ out of 255 ) in the type $1-1$ category and 26 samples (3.4\% out of 757$)$ in the type $2-1$ category were classified as normal according to the untyped reference range, but lowered when referring to their phenotype range. In the case of type 2-2, 36 samples (5.8\% out of 620$)$ were lowered according to the over-all reference range, but normal according to the phenotype reference range. The other discrepancies are between "normal" and "above normal" and are thus not of relevance here.

In total this means that determination of phenotype alters the diagnosis in only 72 samples (10 of type
1-1, 26 of type 2-2 and 36 of type 2-2), which represents only $4 \%$ of the total 1632 samples and $15 \%$ of the samples in the range between 400 and 1170 $\mathrm{mg} / \mathrm{l}$. In all other patient samples the influence of the genetic type is minor, i.e. the sample values are above or below the lower limit of the reference range, whether phenotyped or not.

Another question that now arises is: within these 72 cases, how many patients with established haemolytic diseases would be diagnosed differently without and with phenotyping? Only with these data one can decide whether or not the phenotypic determinations must be performed routinely in large groups of persons with suspected haemolytic disease. Careful examination of the medical records revealed that in a number of patients the haptoglobin determination was performed more than once, so that the 72 determinations under consideration were actually performed on 63 patients. It also appeared from the medical records that only three had an established severe haemolytic disease. The diagnoses were based on a number of clinical features of haemolysis such as jaundice, hepatosplenomegaly and the laboratory approach to the investigation of the anaemia. The other determinations were performed for patients with various diseases including M. Pfeiffer and Werlhof's disease (tab. 2).

Tab. 2. Final diagnosis in which the haptoglobin determinations without and with phenotyping gave a different result.

\begin{tabular}{llr}
\hline Final diagnosis & Haemolysis* & $\mathrm{n}^{* *}$ \\
\hline Haemolysis e. c. i.*** & + & 4 \\
Toxoplasmosis & + & 3 \\
ß-Thalassaemia (heterozygotic) & ++ & 1 \\
Autoimmune haemolytic anaemia & ++ & 1 \\
March haemoglobinuria & ++ & 1 \\
General viral infection & + & 3 \\
Non haemolytic disorders & - & 47 \\
Untrackable & $?$ & 3 \\
\hline
\end{tabular}

* + slight haemolysis ++ severe haemolysis

** In total 60 patients were investigated 69 times for serum haptoglobin. The medical records of 3 patients were not available. *** e causa ignota.

Patients with a haemolysis were present in all three categories of phenotypes. So without withdrawing important clinical information it appeared necessary to perform phenotyping only for those patients with untyped haptoglobin values lying between 400 and $1170 \mathrm{mg} / 1$; these limits are calculated from the reference ranges and RID factors of the three phenotypes. 
With regard to the above results, the clinical chemist can make a contribution to reducing escalating medical costs by decreasing the excessive use of diagnostic tests and procedures. In addition to efforts directed at changing physician's behaviour in asking for unnecessary or inappropiate tests, the clinical chemist should also produce data that carry maximal information. So we decided in our clinic to perform phenotyping only when the untyped values are in the rather narrow range of 400 to $1170 \mathrm{mg} / \mathrm{l}$. In this way we reduce the workload of phenotyping by about $70 \%$, without loss of any important clinical information.

\section{References}

1. Fehr, J. \& Knob, M. (1979) Blood 53, 966-976.

2. Marchand, A., Galen, R. S. \& Van Lente, F. (1980) J. Am. Med. Assoc. 243, 1909-1911.

3. Stathand, B. E., Winkel, P. \& Killingsworth, L. M. (1976) Clin. Chem. 22, 1635-1638.

4. Mancini, G., Carbonara, A. U. \& Heremans, J. F. (1965) Immunochemistry $2,235-254$.
Beyond the scope of this study is the question as to whether this test is ideal for both ruling out and confirming haemolysis. Such an attempt has been made for the haptoglobin determination (2), though some objections against this study have been reported (7). However, with regard to the literature and the results of our study we believe that it is permissible to try to persuade the clinician to abolish phenotyping and therefore accept a less quantitative result beyond the earlier mentioned range; we believe that enough useful clinical information is given by a result obtained in this way.
5. Schrijver, J., Van Rijn, H. J. M. \& Schreurs, W. H. P. (1984) Submitted to Clinical Biochemistry.

6. Van Rijn, H. J. M. \& Schrijver, J. (1983) Haptoglobin typing, is it clinically significant? Abstract Volume $5^{\text {th }}$ Eur. Congress of Clinical Chemistry p. 446.

7. Rice, L. (1980) Letter J. Am. Med. Assoc. 244, 2607-2608.
Dr. H. J. M. van Rijn

Clinical and Haematological Laboratory

Dr. A. Mathijsen Laboratory

NL-3509AA Utrecht 